\title{
Endovascular Management of an Embedded Intracranial Knife
}

\author{
TE Darsaut, RA Ashforth, MM Chow, JM Findlay
}

\begin{abstract}
Background: Endovascular therapy (ET) is infrequently used in the setting of acute penetrating intracranial trauma. Methods: We report a case where ET was used immediately prior to and following removal of an embedded intracranial knife, which was found to be disrupting the anterior cerebral artery. Results: The proximal vessel was coiled and angiographically occluded and then the knife was removed with the microcatheter in place. Immediate angiography allowed us to see and quickly treat the contrast extravasation with further coiling. Despite full medical management, the patient died of elevated intracranial pressure. Conclusion: In this severely injured patient, endovascular therapy represented the most suitable means to attempt safe removal of the knife.
\end{abstract}

RÉSUMÉ: Présence d'un couteau intracrânien : traitement endovasculaire. Contexte : En phase aiguë, on a souvent recours au traitement endovasculaire (TE) dans les traumatismes crâniens pénétrants. Méthodes : Nous présentons un cas chez qui le TE a été utilisé immédiatement avant et après l'ablation d'un couteau intracrânien qui entravait l'artère cérébrale antérieure. Résultats : On a placé des spirales pour occlure le vaisseau proximal au point de vue angiographique et le couteau a été retiré tout en gardant le microcathéter en place. L'angiographie faite surle-champ nous a permis de visualiser une extravasation de l'agent de contraste et de compléter le traitement par la mise en place de spirales. Le patient est décédé d'hypertension intracrânienne malgré un traitement médical intensif. Conclusion : Le traitement endovasculaire était la meilleure option pour tenter de retirer le couteau tout en minimisant les risques chez ce blessé grave.

Can. J. Neurol. Sci. 2007; 34:460-463

Most cases of penetrating craniocerebral trauma with retained foreign body are treated with craniotomy to secure proximal and distal blood vessel control prior to removal of the object. Endovascular treatment may be a useful alternative to craniotomy for the removal of some foreign bodies. Sparing of the parent vessel may be possible following coil or balloon embolization of traumatic pseudoaneurysms, although some intracranial vascular injuries require parent vessel sacrifice. Here we report a case of endovascular management of penetrating arterial disruption following a knife injury to the orbit.

\section{Case Report}

A 32 year-old male butcher with a history of schizophrenia and previous suicide attempts was found unresponsive at his workplace with a butcher knife buried to its handle in his right orbit (Figure 1). On the scene, he was hemodynamically stable with a GCS of 3/15, and he was intubated and transported to the emergency room for evaluation. On examination, he remained unresponsive with a dilated and fixed left pupil, but an intact corneal reflex. Examination of the right eye was not possible due to the presence of the knife.

A computed tomography (CT) scan demonstrated the course of the eight inch knife blade through the medial orbital wall,

From the Department of Surgery (TED, MMC, JMF), Division of Neurosurgery, Department of Radiology (RAA), University of Alberta, Edmonton, Alberta, Canada. ReCeived March 13, 2007. AcCEPTED In FInAl FORM May 27, 2007. Reprint requests to: Tim E. Darsaut, Department of Surgery, Division of Neurosurgery, Mackenzie Health Science Center 2D1.02, 8440 - 112 Street, Edmonton, Alberta, T6G 2B7, Canada. 


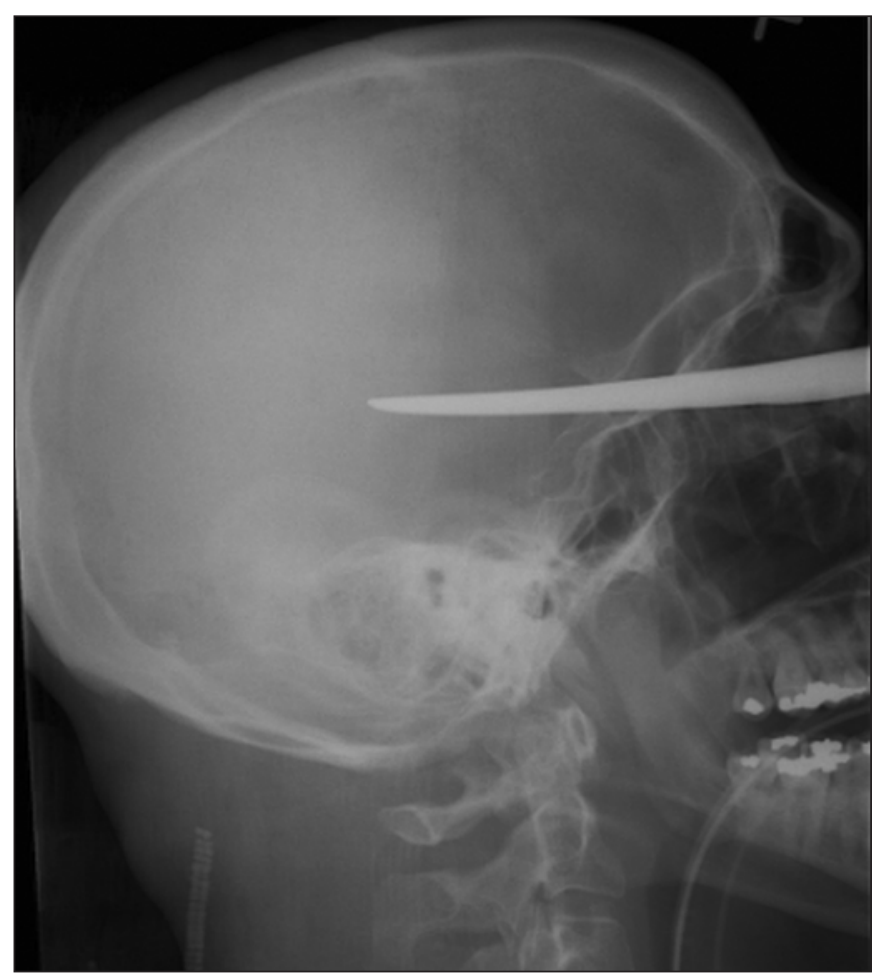

Figure 1: Lateral skull xray showing depth of penetration of knife blade.

along the sphenoid sinus, extending into the left temporal and parietal lobes, with associated subarachnoid blood. There was no associated epidural or subdural hematoma. Any inadvertent movement of the knife was considered to represent a threat to the

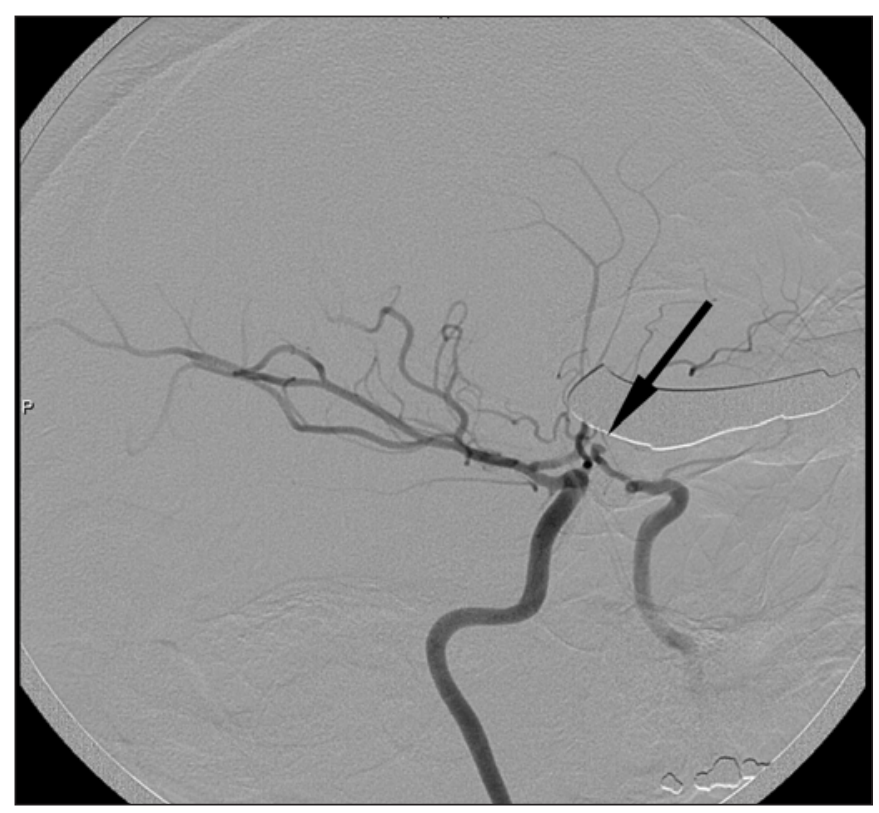

Figure 2: Right internal carotid artery oblique projection demonstrates the $3 \mathrm{~mm}$ traumatic vessel injury near the junction of $A 1$ and $A 2$. patient. As well as mannitol, protective sedation was administered, rendering the neurological examination impossible. We considered the safest means to remove the intracranial knife.

A cerebral angiogram was performed on the suspicion of injury to the vascular tree. The operating room was placed on standby. Angiography revealed the knife in close proximity to the left A2 segment of the anterior cerebral artery, which was occluded distally, leaving a $3 \mathrm{~mm}$ stump of the A2 arterial segment (Figure 2). The precariously positioned knife would have made performing a craniotomy dangerous and difficult, so the decision was made to proceed with endovascular treatment. A 45 degree angled Excelsior SL-10 microcatheter (Boston Scientific, Fremont, CA) was navigated into the stump over a

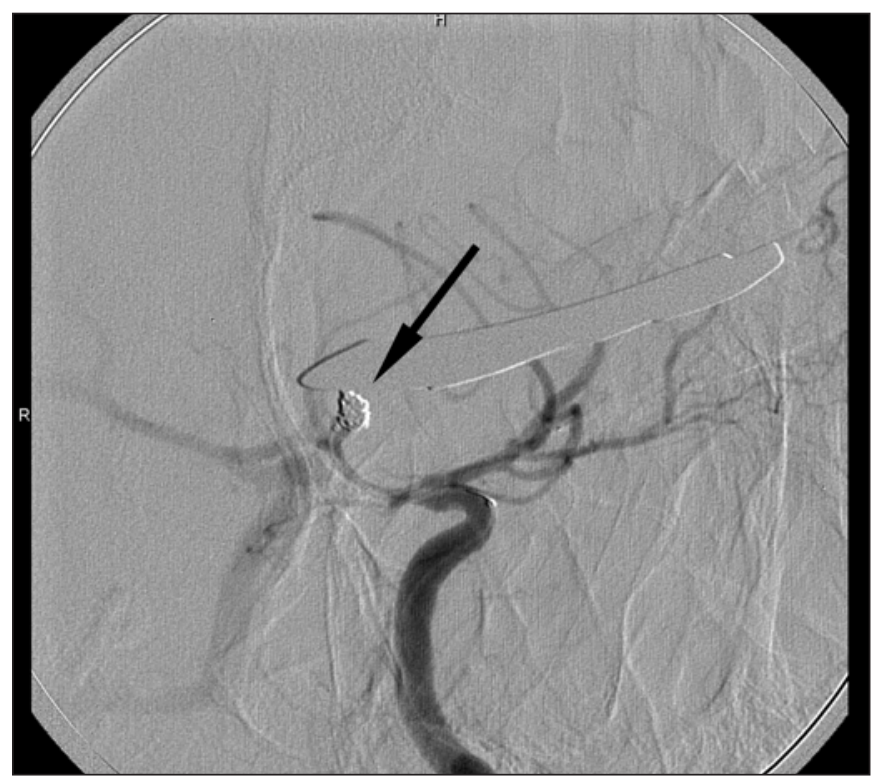

Figure 3: Oblique projection of left internal carotid injection following deposition of three embolic coils in the arterial stump.

Synchro-14 guidewire (Boston Scientific, Fremont, CA), and a $3 \mathrm{~mm} \times 6 \mathrm{~cm}$ GDC 10360 o soft framing coil (Boston Scientific, Fremont, CA) was deployed. This was followed by two smaller coils $(2.5 \mathrm{~mm} \times 4 \mathrm{~cm}$ GDC 10 ultrasoft and $2 \mathrm{~mm} \times 4 \mathrm{~cm}$ GDC 10 ultrasoft) to achieve angiographic occlusion of the A2 segment (Figure 3). Since the knife blade was in close proximity to the stump, the microcatheter was left in position, and a temporary balloon occlusion catheter was readied in preparation for removal of the knife in the angiography suite. Immediately following removal of the foreign body, an angiographic run demonstrated contrast extravasation from the coiled vessel stump (Figure 4), so two more coils (2.5 mm x $4 \mathrm{~cm}$ GDC 10 ultrasoft and $2 \mathrm{~mm}$ x $3 \mathrm{~cm}$ GDC 10 ultrasoft), were quickly 


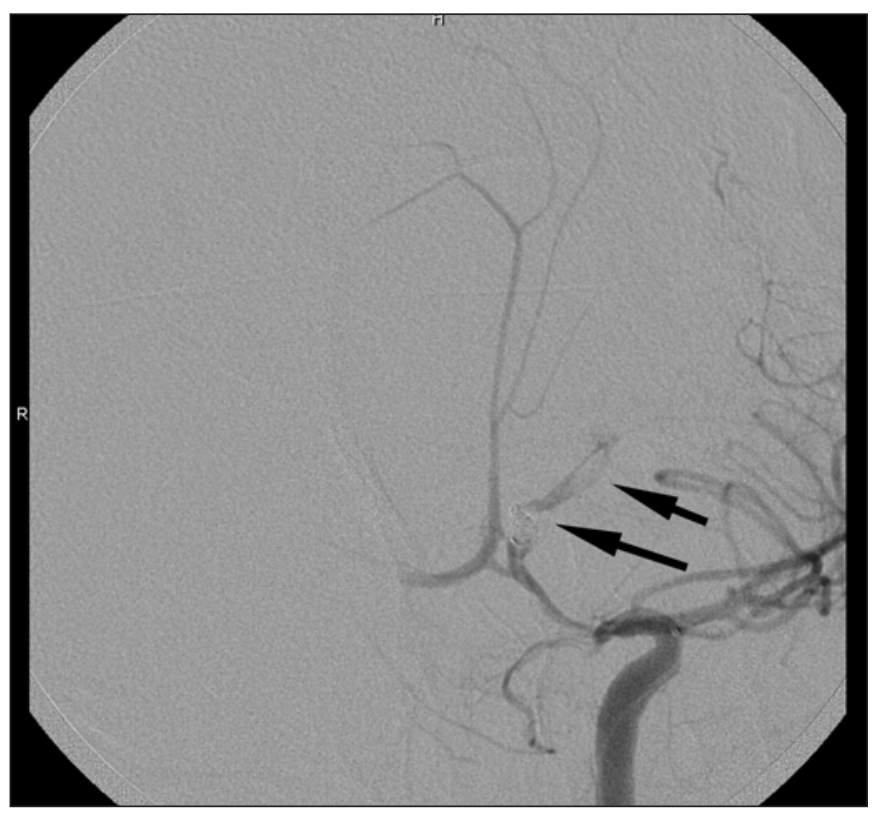

Figure 4: Oblique projection of left internal carotid injection demonstrating contrast extravasation following removal of the knife.

deployed, and the extravasation stopped (Figure 5). An immediate follow-up CT scan was performed following embolization, which demonstrated a deep left temporal intracerebral hemorrhage separate from the site of the anterior cerebral artery injury (Figure 6), likely from small vessels along the knife blade tract.

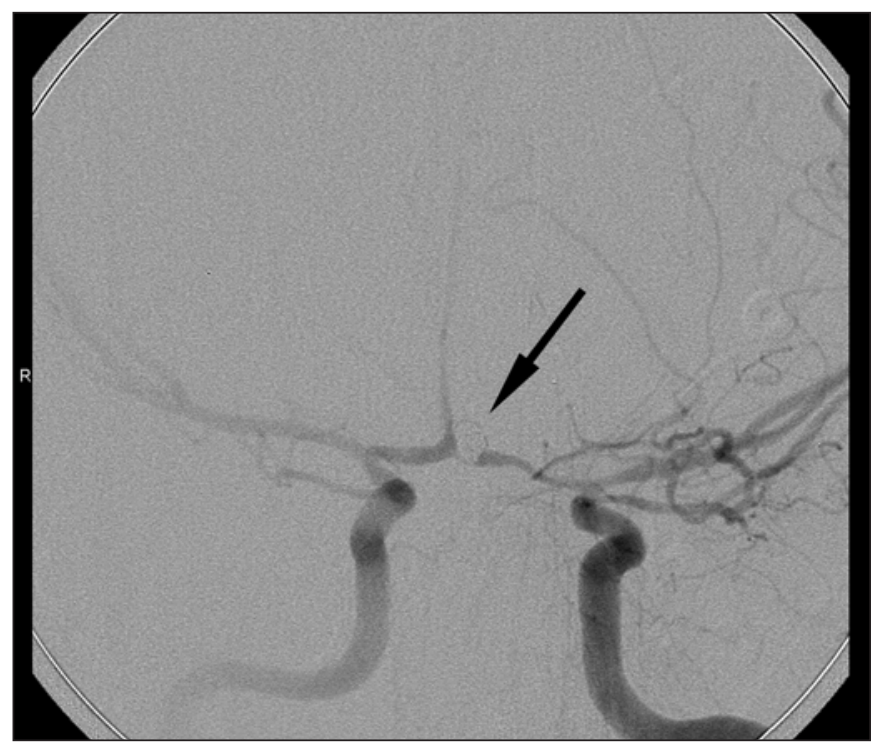

Figure 5: AP projection of left internal carotid injection showing no further extravasation after deposition of two more coils.

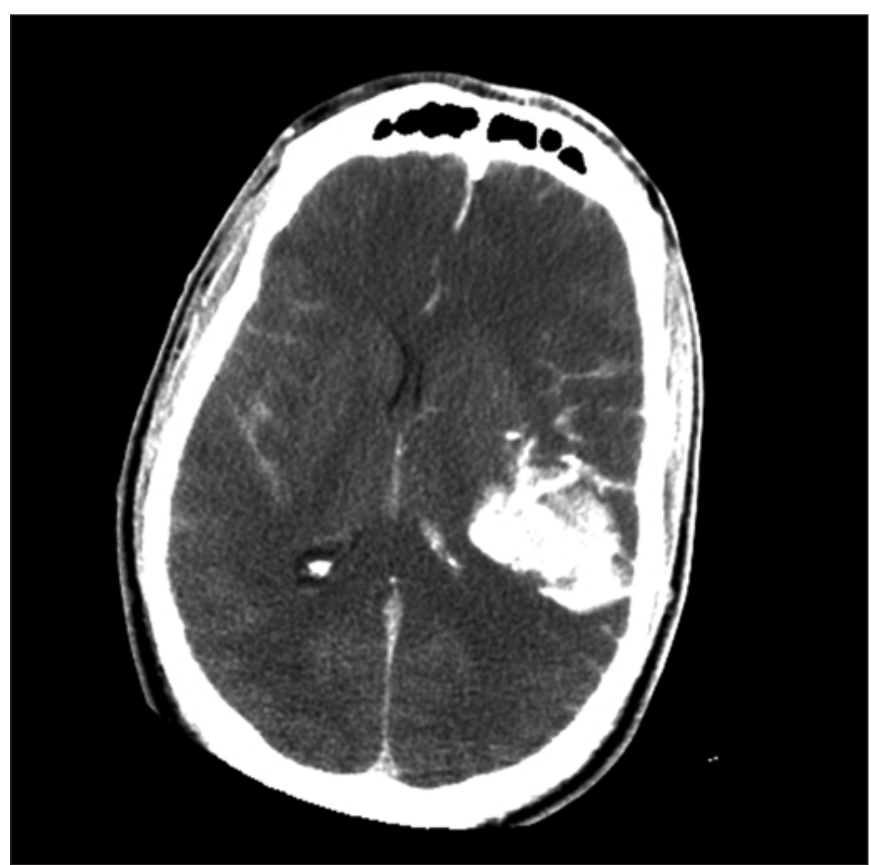

Figure 6: CT head showing deep temporal hemorrhage, along the knife tract but away from the site of the arterial disruption.

The patient was transported to the neuro intensive care unit, where an intraparenchymal monitor was placed, confirming an intracranial pressure (ICP) of $70 \mathrm{~cm} \mathrm{H}_{2} \mathrm{O}$. Despite full medical management, the ICP remained elevated, and active treatment was withdrawn 12 hours following the endovascular intervention. The patient died shortly thereafter. Unfortunately, the family declined autopsy.

\section{Discussion}

The principles of management of non-missile penetrating intracranial foreign objects are to assess the extent of damage to cerebral and vascular structures, to secure proximal and distal control, and remove the foreign body to reduce the risk of infection, seizures, and prevent further injury. This is traditionally accomplished by clinical assessment, computed tomography, and angiography followed by craniotomy. ${ }^{1-3}$ More recently, in highly select cases, endovascular treatment has been suggested as a useful adjunct in the surgical removal of intracranial foreign bodies. ${ }^{4}$

Endovascular coils have been used successfully to treat traumatic aneurysms in a delayed fashion, ${ }^{5,6}$ but to the best of our knowledge there are no reports of endovascular embolization used to treat acute vascular injuries with the foreign object still in situ. There is one report of successful removal of a foreign body (an eyeglass earpiece) from the cavernous sinus with temporary balloon occlusion of the cavernous internal carotid artery. ${ }^{4}$ The major risks of endovascular treatment in this setting are uncontrollable hemorrhage from vessels along the wound tract and ischemic stroke following parent vessel sacrifice. 
Endovascular management offers the benefit of avoiding the risks of craniotomy, which is especially fraught with peril, both in the acute setting and in the treatment of traumatic pseudoaneurysms, which have friable walls and do not usually have necks suitable for clipping. ${ }^{3}$ Endovascular management also allows for immediate follow-up angiography, which was important in this case, as removal of the knife resulted in new hemorrhage. It should be stressed that the neuro-interventionist should have occlusive balloons prepared for deployment in the event that embolic coils fail to staunch the hemorrhage.

Most published cases where removal of the foreign body did not result in a fatal outcome have involved patients with better presenting neurological status. The potential danger represented by leaving the knife in situ for a period of observation compelled us to attempt to remove the knife. Although a 'pull and see' policy has been advocated, ${ }^{7}$ angiographic visualization with endovascular control of the proximal injured vessel was felt to represent a better alternative in spite of the clinical suspicion of a devastating neurological injury. The poor clinical status of the patient prior to the removal of the knife makes it difficult to determine whether the angiographically satisfactory coiling of the traumatically injured vessel might have resulted in a successful clinical outcome if the primary neurological injury had not been as significant.

\section{CONCLUSION}

Endovascular management of acute penetrating injuries to the intracranial vasculature before and after foreign body removal remains a viable treatment option. For the removal of a penetrating foreign body in the acute setting, endovascular treatment may be favoured in circumstances where surgical management promises to be technically difficult or poorly tolerated by the patient, or when poor neurological condition does not warrant craniotomy.

\section{REFERENCES}

1. Sani S, Jobe KW, Byrne RW. Successful repair of an intracranial nail-gun injury involving the parietal region and the superior sagittal sinus. Case report. J Neurosurg. 2005;103(3):567-9.

2. Litvack ZN, Hunt MA, Weinstein JS, West GA. Self-inflicted nailgun injury with 12 cranial penetrations and associated cerebral trauma. Case report and review of the literature. J Neurosurg. 2006;104(5):828-34.

3. Amirjamshidi A, Rahmat H, Abbassioun K. Traumatic aneurysms and arteriovenous fistulas of intracranial vessels associated with penetrating head injuries occurring during war: principles and pitfalls in diagnosis and management. A survey of 31 cases and review of the literature. J Neurosurg. 1996;84(5):769-80.

4. Cunningham EJ, Albani B, Masaryk TJ, Rasmussen PA. Temporary balloon occlusion of the cavernous carotid artery for removal of an orbital and intracranial foreign body: case report. Neurosurgery 2004;55(5):1225.

5. Tokunaga K, Kusaka N, Nakashima H, Date I, Ohmoto T. Coil embolization of intradural pseudoaneurysms caused by arterial injury during surgery: report of two cases. AJNR Am J Neuroradiology. 2001;22(1):35-9.

6. Lempert TE, Halbach VV, Higashida RT, Dowd CF, Urwin RW, Balousek PA, et al. Endovascular treatment of pseudoaneurysms with electrolytically detachable coils. AJNR Am J Neuroradiology. 1998;19(5):907-11.

7. Rao GP, Rao NS, Reddy PK. Technique of removal of an impacted sharp object in a penetrating head injury using the lever principle. Br J Neurosurg. 1998;12(6):569-71. 